\title{
Hyperinsulinaemic-hypoglycaemic glucose clamps in human research: a systematic review of the literature
}

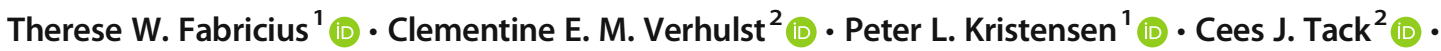 \\ Rory J. McCrimmon ${ }^{3}$ (D) Simon Heller ${ }^{4}$ (D) Mark L. Evans $^{5}$ (D) - Stephanie A. Amiel ${ }^{6}$ (D) Thomas R. Pieber $^{7}$ (D) \\ Bastiaan E. de Galan $^{2,8}$ (D) - Ulrik Pedersen-Bjergaard ${ }^{1,9}$ (D) - on behalf of the Hypo-RESOLVE consortium
}

Received: 10 July 2020 / Accepted: 9 November 2020 / Published online: 10 February 2021

(C) The Author(s) 2020

\begin{abstract}
Aims/hypothesis The hyperinsulinaemic-hypoglycaemic glucose clamp technique has been developed and applied to assess effects of and responses to hypoglycaemia under standardised conditions. However, the degree to which the methodology of clamp studies is standardised is unclear. This systematic review examines how hyperinsulinaemic-hypoglycaemic clamps have been performed and elucidates potential important differences.

Methods A literature search in PubMed and EMBASE was conducted. Articles in English published between 1980 and 2018 , involving adults with or without diabetes, were included.

Results A total of 383 articles were included. There was considerable variation in essential methodology of the hypoglycaemic clamp procedures, including the insulin dose used (49-fold difference between the lowest and the highest rate), the number of hypoglycaemic steps (range 1-6), the hypoglycaemic nadirs (range 2.0-4.3 mmol/l) and the duration (ranging from 5 to $660 \mathrm{~min}$ ). Twenty-seven per cent of the articles reported whole blood glucose levels, most venous levels. In $70.8 \%$ of the studies, a dorsal hand vein was used for blood sampling, with some form of hand warming to arterialise venous blood in $78.8 \%$ of these. Key information was missing in $61.9 \%$ of the articles.

Conclusions/interpretation Although the hyperinsulinaemic-hypoglycaemic clamp procedure is considered the gold standard to study experimental hypoglycaemia, a uniform standard with key elements on how to perform these experiments is lacking. Methodological differences should be considered when comparing results between hypoglycaemic clamp studies.

PROSPERO registration This systematic review is registered in PROSPERO (CRD42019120083).
\end{abstract}

Keywords Diabetes · Diabetes mellitus · Human - Hyperinsulinaemic-hypoglycaemic clamp $\cdot$ Hypoglycaemia $\cdot$ Systematic review · Type 1 diabetes $\cdot$ Type 2 diabetes

Therese W. Fabricius and Clementine E.M. Verhulst share first authorship. Bastiaan E. de Galan and Ulrik Pedersen-Bjergaard share last authorship.

Therese W. Fabricius

therese.emilie.wilbek.fabricius@ regionh.dk

Clementine E. M. Verhulst

clementine.verhulst@radboudumc.nl

1 Department of Endocrinology and Nephrology, Nordsjællands Hospital, Hillerød, Denmark

2 Department of Internal Medicine, Radboud University Medical Centre, Nijmegen, the Netherlands

3 Department of Internal Medicine, University of Dundee, Dundee, UK
4 Department of Oncology and Metabolism, University of Sheffield, Sheffield, UK

5 Wellcome Trust/MRC Institute of Metabolic Science, University of Cambridge, Cambridge, UK

6 Department of Diabetes, School of Life Course Sciences, Faculty of Life Sciences \& Medicine, King's College London, London, UK

7 Division of Endocrinology and Diabetology, Department of Internal Medicine, Medical University of Graz, Graz, Austria

8 Department of Internal Medicine, Maastricht University Medical Centre, Maastricht, the Netherlands

9 Department of Clinical Medicine, Faculty of Health and Medical Sciences, University of Copenhagen, Copenhagen, Denmark 


\section{Research in context}

\section{What is already known about this subject?}

- The hyperinsulinaemic-hypoglycaemic clamp technique was developed and is widely used to assess and quantify effects of hypoglycaemia under uniform conditions

- The term 'hyperinsulinaemic-hypoglycaemic clamp' suggests the existence of a uniformly agreed standard operating procedure

- The degree to which clamps are indeed performed according to standard methodology is unclear

\section{What is the key question?}

- What are the differences and similarities in the methodology and reporting of hyperinsulinaemic-hypoglycaemic clamps?

\section{What are the new findings?}

- There is substantial variation in essential methodological aspects of the hyperinsulinaemic-hypoglycaemic clamp, including pre-clamping preparation, method of glucose sampling, insulin dose, hypoglycaemic nadirs and duration, and number of hypoglycaemic steps

- Essential methodological information is missing in $61.9 \%$ of the articles

How might this impact on clinical practice in the foreseeable future?

- This systematic review clarifies the major differences in the performance of the hyperinsulinaemic-hypoglycaemic clamp

\author{
Abbreviations \\ BSA Body surface area \\ CGM Continuous glucose monitoring \\ GIR Glucose infusion rate \\ IHSG International Hypoglycaemia Study Group \\ IIR Insulin infusion rate \\ PRISMA Preferred Reporting Items for Systematic \\ Reviews and Meta-Analyses
}

\section{Introduction}

Despite important advances in the manufacturing of insulin agents, insulin administration and glucose monitoring, hypoglycaemia remains the most frequent adverse event in people with diabetes treated with insulin and is associated with increased morbidity and mortality [1]. Revealing the still many knowledge gaps in understanding the pathophysiology of, responses to and effects of hypoglycaemia is therefore important.

In the 1970 s, the hyperinsulinaemic-normoglycaemic clamp technique was developed for quantification of beta cell sensitivity to glucose and of tissue sensitivity to insulin [2, 3]. The hyperinsulinaemic-hypoglycaemic clamp technique is a variant of this method, designed to assess clinical manifestations of hypoglycaemia, including counterregulatory hormone responses, symptomatic awareness and cognitive function, under standardised conditions $[4,5]$. It consists of continuous intravenous insulin infusion at a (relatively) high dose to ensure sufficient glucose lowering and a variable infusion of glucose guided by glucose measurements performed at regular time intervals to achieve stable glucose values at pre-defined target(s). Two forms can be distinguished, involving either a single glucose target (single-step clamp) or multiple decremental targets in the hypoglycaemic range (stepped clamp).

A universally accepted standardised protocol for the hyperinsulinaemic-hypoglycaemic clamp would allow for meta-analysis with increased statistical power when different studies are compared. However, to the best of our knowledge, no previous article has been published that sets out standards for performing hypoglycaemic clamp experiments, for instance with respect to the optimal glucose target or duration of the clamp. Differences in its execution may affect the validity when data from clamp studies are compared or render it impossible to compare study results. In this review, we provide a comprehensive overview on how hyperinsulinaemic-hypoglycaemic clamps have been performed in humans and elucidate differences and similarities in their execution.

\section{Methods}

We performed a descriptive systematic review in accordance with the published protocol in PROSPERO (https://www.crd. york.ac.uk/prospero/display_record.php?RecordID=120083). All peer-reviewed articles available online reporting 
hyperinsulinaemic-hypoglycaemic clamps involving adults with type 1 diabetes or type 2 diabetes or without diabetes (healthy participants) were included. Only English language articles were included in this review. All articles from studies in which participants had undergone a hyperinsulinaemichypoglycaemic clamp were read. If multiple articles were published from the same study, only the first published article with a sufficient clamp description was included, and the hyperinsulinaemic-hypoglycaemic clamp needed to be the main method of the study. Studies involving animals or with inadequate descriptions on how the clamp was performed were excluded. Reporting is in accordance with the Preferred Reporting Items for Systematic Reviews and Meta-Analyses (PRISMA) guidelines [6].

\section{Data sources and search strategy}

A literature search was conducted in PubMed and EMBASE in November 2018. All articles available online in the databases were included, resulting in the inclusion of articles from 1980 to 2018. The search used a combination of free text words and MeSH (PubMed) and Emtree (EMBASE) terms. All titles and abstracts identified from the electronic search via PubMed and EMBASE were imported to COVIDENCE software, version 1.0 (https://www.covidence.org/), accessed in November 2018, a program that streamlines the review process. The search strategy was developed in collaboration with an information specialist at Nordsjællands Hospital with input from clinicians and academics in the review team. The search strategy for PubMed is available in the supplementary material (electronic supplementary material [ESM] Methods).

\section{Study selection}

Duplicates from the two searches were automatically removed when imported into COVIDENCE, version 1.0 (https://www. covidence.org/), accessed in November 2018. All titles and abstracts were assessed independently to identify articles requiring full-text review against the inclusion and exclusion criteria. This first step was done by one reviewer (T.W. Fabricius), using the words 'clamp' and 'hypoglycaemia'. Eligible articles identified after title and abstract review underwent all full-text reading, and the reference lists were searched for other articles. This step was carried out by two reviewers (T.W. Fabricius and C.E.M. Verhulst). For this review we focused on type 1 diabetes, type 2 diabetes and people without diabetes; studies in children were included. Studies exclusively performed in patients with other conditions were excluded (ESM Methods). An extraction sheet was used to extract the desired information from each article. Any disagreements between the reviewers were resolved by consensus and in consultation with one of the senior authors (U. Pedersen-Bjergaard and B.E. de Galan). The list of the included articles is shown in the supplementary material (ESM Methods, ESM Table 1).

\section{Data extraction}

We extracted information from the articles with our main focus on the procedure and the quality of the clamp, including duration of the clamp, number of glucose steps, glucose levels targeted and achieved, duration of target glucose levels, type of insulin and insulin infusion rates (IIRs) used, source of blood sampling (venous, arterial, capillary; arterialisation method in the case of venous blood) and type of glucose analyser used. Furthermore, we collected study characteristics such as author identification, year of publication, type of study and characteristics of the study population.

\section{Statistics}

Results are shown with descriptive statistical methods. We report the continuous data as means with standard deviations in the case of normal distribution, and as medians with interquartile ranges when data are not normally distributed. Statistical analyses were performed using IBM SPSS Statistics version 25. A $p$ value $<0.05$ was considered statistically significant.

\section{Results}

A total of 3885 articles were found on PubMed and EMBASE (Fig. 1). After the process of screening, 408 articles fulfilled the inclusion criteria, after which 25 articles were excluded because of inadequate clamp description. A total of 383 articles were thus included for analysis. In total, $38.1 \%$ of the 383 articles (146 articles) contained all information on the clamp procedures for which we searched.

\section{Participants}

The 383 articles analysed included a total of 6993 participants. The median number of participants in the studies was 15 (IQR: 10-22). Most of the participants examined in the studies were healthy individuals, followed by participants with type 1 diabetes, with only a few studies enrolling people with type 2 diabetes. There was a preponderance of male participants in the studies and the participants were relatively young (Table 1).

\section{Instructions and preparation}

Most of the hyperinsulinaemic-hypoglycaemic clamps were scheduled in the morning. In $80.9 \%$ of all studies, participants were instructed to fast overnight prior to the clamp day. In 
Fig. 1 PRISMA flow diagram
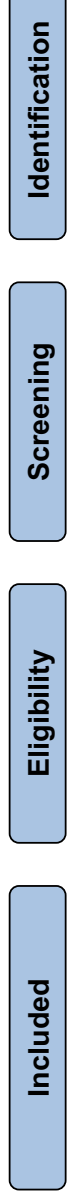

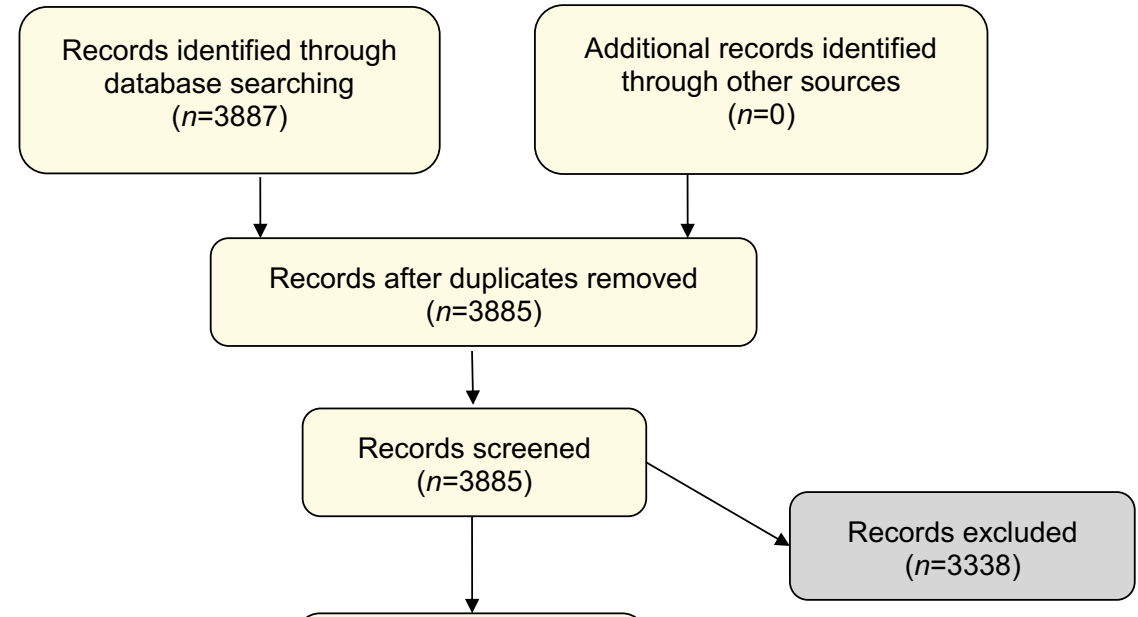

Full-text articles assessed for eligibility $(n=547)$

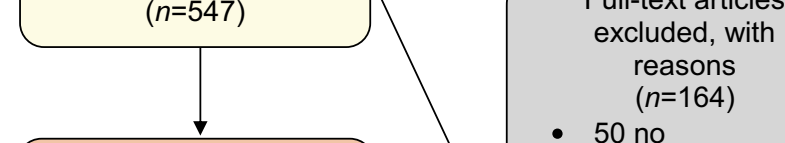

Studies included in qualitative synthesis $(n=383)$

Studies included in quantitative synthesis (meta-analysis) $(n=383)$
- 50 no hypoglycaemic clamp performed

- 35 other patient population

- 25 inadequate clamp description

- 25 previously published

- 21 not main article

- 4 not in English

- 4 animal studies
Table 1 Baseline characteristics of participants

\begin{tabular}{llll}
\hline Characteristic & Type 1 diabetes & Type 2 diabetes & No diabetes \\
\hline No. articles (\%) & $174(45.4)$ & $30(7.8)$ & $268(70.0)$ \\
No. participants (\%) & $2768(39.6)$ & $485(6.9)$ & $3740(53.5)$ \\
Age, years & $31.6 \pm 7.8$ & $55.1 \pm 8.4$ & $30.7 \pm 12.6$ \\
Male sex, $\%$ & 62.8 & 67.6 & 65.0 \\
$\mathrm{HbA}_{1 \mathrm{c}}$ & & & \\
$\mathrm{mmol}_{\text {mol }}$ & $65 \pm 16$ & $60 \pm 13$ & $34 \pm 4$ \\
$\quad \%$ & $8.1 \pm 1.4$ & $7.7 \pm 1.2$ & $5.3 \pm 0.3$ \\
Diabetes duration, years & $14.3 \pm 6.0$ & $9.3 \pm 5.4$ & $24.0 \pm 2.2$ \\
BMI, kg/m & $24.4 \pm 1.9$ & $29.6 \pm 2.6$ & \\
Type 2 diabetes glucose-lowering treatment $(\%)$ & & \\
Diet & & $7(23.3)$ & \\
Oral agents alone & $28(93.3)$ & \\
Insulin & & $15(50)$ & \\
Not provided & & $1(3.3)$ & \\
\hline
\end{tabular}

Data are shown as $n(\%)$ or mean $( \pm \mathrm{SD})$ 
$21.4 \%$ of the articles there were other dietary restrictions such as a weight-maintaining diet 3 days before the clamp $(n=40$, $10.4 \%$ ), a standardised meal the evening before the clamp $(n=12,3.1 \%)$ or a standard breakfast on the morning of the clamp $(n=8,2.1 \%)$ (ESM Table 2). Participants were also instructed to abstain from drinking alcohol (13.6\%), smoking tobacco $(4.7 \%)$, engaging in exercise $(11.5 \%)$ and ingesting caffeine ( $8.6 \%$ ). In $23.0 \%$ of the experiments involving people with diabetes, an overnight low-dose insulin infusion was provided to normalise glucose levels prior to the clamp. In $3.9 \%$ of the experiments, participants were instructed to measure or monitor blood glucose overnight by finger stick or continuous glucose monitoring (CGM) to ensure avoidance of nocturnal hypoglycaemia, which necessitated rescheduling of the clamp.

\section{Clamp procedure}

Human soluble insulin was used in $65.5 \%$ of the clamps, a rapid-acting analogue insulin in $1.6 \%$ and both types of insulin in $0.5 \%$, whereas $32.4 \%$ of the articles did not report the type of insulin used (about $42.6 \%$ of which were published before market introduction of insulin analogues). Glucose (or dextrose) was administered as a $20 \%$ solution in $74.7 \%$ of the studies and as another solution in $6.5 \%$, whereas $18.8 \%$ of the articles did not provide the glucose percentage used.

Two methods were used to calculate the IIR, i.e. based on body weight ( $\mathrm{mU}$ or pmol kg${ }^{-1} \mathrm{~min}^{-1}$ ) in 257 articles $(67.1 \%)$ or on body surface area (BSA) (mU or pmol m${ }^{-2} \mathrm{~min}^{-1}$ ) in 110 articles (28.7\%). Sixteen articles (4.2\%) did not report how the IIR was calculated. There was considerable variation in IIR across studies, ranging from 0.25 to $12.0 \mathrm{mU} \mathrm{kg}^{-1} \mathrm{~min}^{-1}$ for studies calculating IIR by body weight and from 15 to

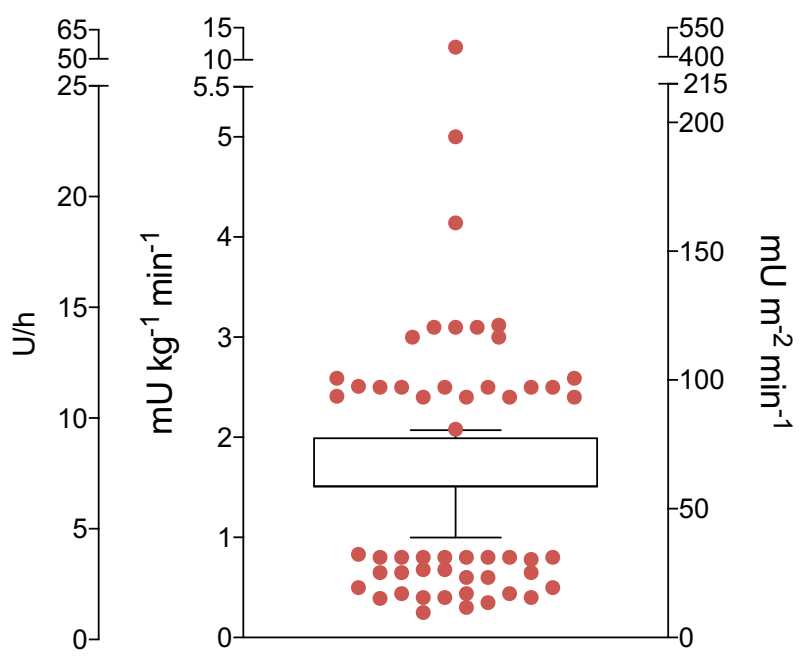

Fig. 2 Individual IIRs are shown in a box, representing 25th-75th percentiles, and whiskers showing 10th and 90th percentiles, and are expressed in units per hour $(\mathrm{U} / \mathrm{h}), \mathrm{mU} \mathrm{kg}^{-1} \mathrm{~min}^{-1}$ and $\mathrm{mU} \mathrm{m} \mathrm{min}^{-1}$, normalised for a 'standard person' with a weight of $75 \mathrm{~kg}$ and a height of $180 \mathrm{~cm}$
$160 \mathrm{mU} \mathrm{m}{ }^{-2} \mathrm{~min}^{-1}$ for studies using body surface area (Fig. 2). When recalculating IIR to a person of average body weight and height $(75 \mathrm{~kg}, 180 \mathrm{~cm})$, mean \pm SD IRR corresponded to $7.1 \pm 4.1 \mathrm{U} / \mathrm{h}$ (range 1.1-54.0 U/h) based on body weight and $7.7 \pm 2.6 \mathrm{U} / \mathrm{h}$ (range 1.75-18.6 U/h) based on BSA, respectively. There were no significant differences in the IIR between the single-step and stepped clamps, although in 38 (9.9\%) of the latter the IIR was increased to reach the deepest hypoglycaemic level. Information about the glucose infusion rate (GIR) was provided by $24.8 \%$ of the studies.

Of the studies reporting plasma insulin levels during the clamp ( $n=147,38.4 \%)$, the mean CVs of these levels for IIR based on body weight and BSA were $28 \pm 16$ vs $32 \pm$ $35 \%(p=0.70)$, respectively.

In $89.0 \%$ of the clamps, venous blood was sampled for glucose and other measurements, whereas arterial blood was sampled in $2.3 \%$. Four articles reported both venous and arterial blood sampling and $7.6 \%$ of the studies did not specify the source of blood sampling. Glucose was measured in plasma in 271 articles $(70.8 \%)$ and in whole blood in 105 (27.4\%), with 7 articles (1.8\%) not providing this information. Because of the different methods of glucose measurement, we converted whole blood glucose values to plasma glucose values, assuming plasma glucose levels to be $11.1 \%$ higher compared with whole blood measurements [7]. The most widely reported location of the venous catheter for blood sampling was in a dorsal hand vein (70.9\%), followed by veins in the antecubital region $(6.8 \%)$, the forearm $(6.2 \%)$ and the leg $(0.8 \%)$. In $15.3 \%$ of the articles, the location of the catheter was not provided.

A method for arterialisation of venous blood was reported by $272(78.8 \%)$ of the studies using venous cannulations. The methods used to arterialise venous blood varied, but the application of a heated hand box method was used most often (66.4\%), followed by the use of a blanket (4.6\%), a pad (1.7\%), other means $(1.7 \%)$ or an unspecified method $(4.3 \%)$. In $21.2 \%$ of the articles, hand warming was not applied. Of all the 229 studies that used a heated box, its temperature was set at $50-60^{\circ} \mathrm{C}$ in $48.5 \%$, at $60-70^{\circ} \mathrm{C}$ in $30.1 \%$ or at $60^{\circ} \mathrm{C}$ in $15.7 \%$ of the experiments. A temperature below $50^{\circ} \mathrm{C}$ was used in $1.3 \%$ of the articles and $4.4 \%$ did not provide the target temperature of the heated box. In two studies, arterialisation of venous blood was checked by blood gas analyses.

Glucose levels were measured at $5 \mathrm{~min}$ intervals in $82.5 \%$ of the studies. Shorter time intervals (down to $1.5 \mathrm{~min}$ ) were used in $10.0 \%$ and longer intervals up to $30 \mathrm{~min}$ in $7.5 \%$ of the studies. Glucose levels were mostly determined with the Beckman Glucose Analyzer (39.2\%) or the Yellow Spring Instruments Glucose Analyzer (36.0\%). At regular intervals, blood was drawn to determine counterregulatory hormones, i.e. glucagon, catecholamines, growth hormone and cortisol, in $86.2 \%$ of the studies.

From 222 articles $(58.0 \%)$, it was possible to extract $(n=18)$ or calculate $(n=204)$ the CV of glucose levels achieved during the clamp. In studies where this was 
calculated, the $\mathrm{CV}$ of the normoglycaemic and hypoglycaemic phases averaged $7 \pm 6 \%$ and $10 \pm 9 \%$, respectively $(p<0.0005)$. The overall mean CV of the normo- and hypoglycaemic phases combined in these clamps was $8.3 \pm$ $7 \%$, with 72 clamps (32.4\%) having a mean $\mathrm{CV}<5 \%, 91$ (41\%) a mean CV of $5-10 \%, 51(23.0 \%)$ a mean CV of $11-$ $20 \%$ and eight a mean CV of more than $20 \%$. Of the 18 articles reporting the calculated $\mathrm{CV}$, all had a $\mathrm{CV}<10 \%$.

\section{Type of clamp}

A single-step hypoglycaemic clamp was performed in 245 (64.0\%) of the articles and a stepped clamp in 135 (35.2\%), whereas three $(0.8 \%)$ articles applied both single-step and stepped clamps on separate days.

Single-step clamp In 192 of the 248 articles (77.4\%) using single-step clamps, a normoglycaemic phase preceded the hypoglycaemic phase, the duration of which ranged from 15 to $330 \mathrm{~min}$, with $30 \mathrm{~min}(23.0 \%), 60 \mathrm{~min}(17.7 \%)$ or $120 \mathrm{~min}$ (12.9\%) most often used. After correction of whole blood glucose values into plasma values (see Clamp procedure), the mean plasma glucose level of the normoglycaemic phase was $5.2 \pm 0.8 \mathrm{mmol} / \mathrm{l}$. The duration of the hypoglycaemic phase ranged from 5 to $660 \mathrm{~min}$; most had a duration of 30 , 60 or $120 \mathrm{~min}$. The mean glucose level at hypoglycaemic nadir was $2.8 \pm 0.4 \mathrm{mmol} / \mathrm{l}$, but there was considerable variation across the studies (ESM Fig. 1). In 173 articles (69.8\%), the glucose nadir was $<3.0 \mathrm{mmol} / \mathrm{l}$ (mean $2.7 \pm 0.2 \mathrm{mmol} / \mathrm{l}$, range 2.0-2.9), corresponding to level 2 hypoglycaemia according to the International Hypoglycaemia Study Group (IHSG) classification [8], whereas the nadir was $\geq 3.0 \mathrm{mmol} /$ 1 (mean $3.2 \pm 0.2 \mathrm{mmol} / \mathrm{l}$, range $3.0-4.3$ ) in 75 articles $(30.2 \%)$.

Stepped clamp Experiments using stepped clamps varied in the number of steps (range 1-6). The most frequently used number of steps after the normoglycaemic phase was four (36.2\%), three (25.4\%) or two (19.6\%). More than four steps were used in $10.1 \%$ of articles, whereas $4.3 \%$ did not provide information on the number of steps and $4.3 \%$ had a hyperglycaemic step included.

There was a large variation in the duration of the hypoglycaemic phases for the stepped clamp studies. In the studies that used four steps, the duration ranged from 20 to $90 \mathrm{~min}$ per step, the majority using $45 \mathrm{~min}(33.3 \%), 60 \mathrm{~min}$ $(25.0 \%)$ or $40 \mathrm{~min}(18.8 \%)$. The duration of the steps for three-step clamps ranged from 20 to 90 min per step, with $60 \min (31.6 \%), 30 \min (21.1 \%)$ or $50 \min (13.2 \%)$ most frequently applied.

In the four-step clamps, the mean targeted plasma glucose levels for the consecutive steps were $4.2 \pm 0.3 \mathrm{mmol} / \mathrm{l}, 3.6 \pm$ $0.2 \mathrm{mmol} / 1,3.0 \pm 0.2 \mathrm{mmol} / 1$ and $2.5 \pm 0.2 \mathrm{mmol} / 1$,
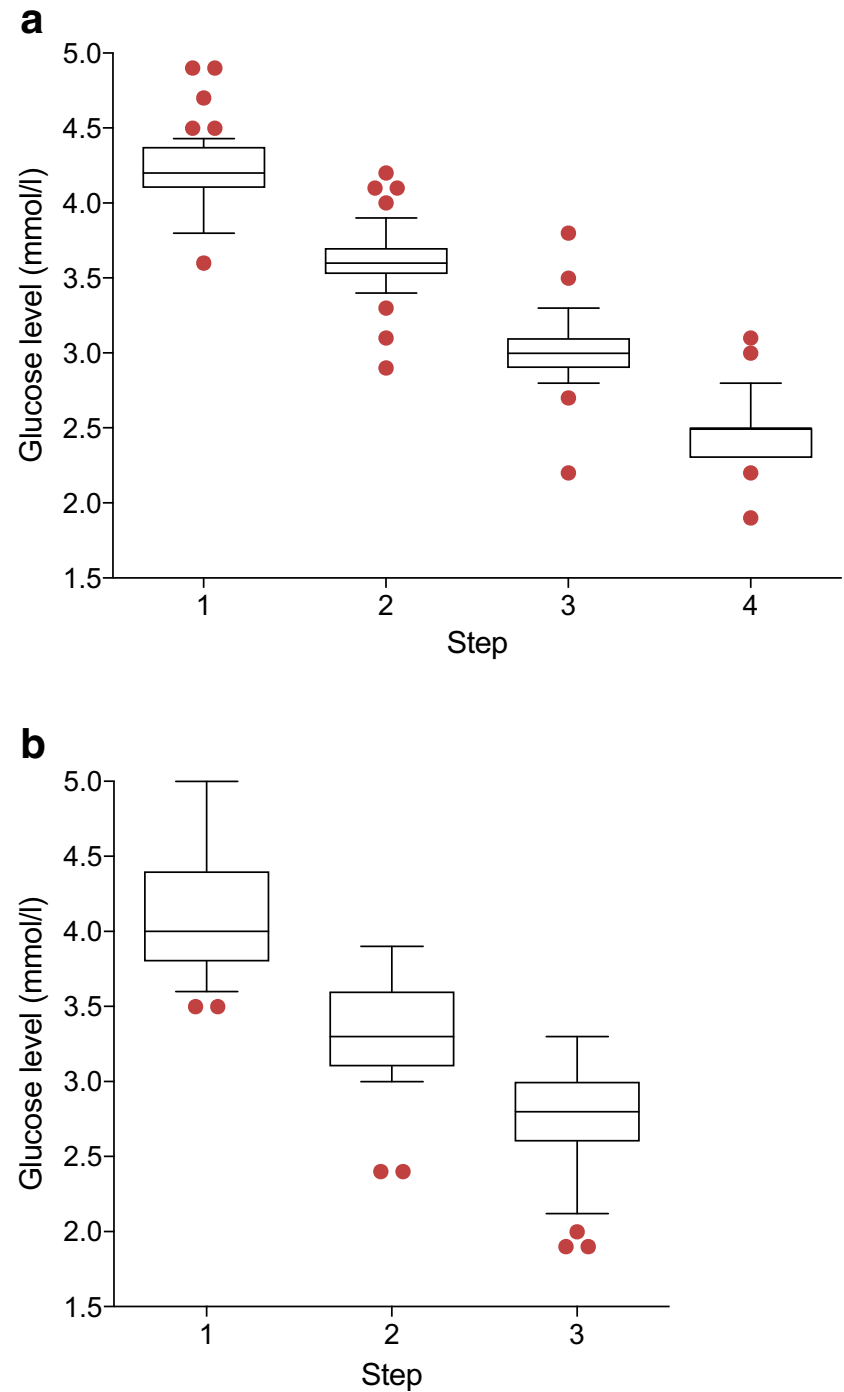

Fig. 3 Hypoglycaemic steps in (a) four-stepped and (b) three-stepped clamps. Data are shown in a box, representing 25 th-75th percentiles, and whiskers showing 10th and 90th percentiles

respectively (Fig. 3a). For the three-step clamps, these numbers averaged $4.1 \pm 0.4 \mathrm{mmol} / \mathrm{l}, 3.4 \pm 0.4 \mathrm{mmol} / \mathrm{l}$ and $2.8 \pm 0.4 \mathrm{mmol} / \mathrm{l}$ (Fig. 3b). The mean glucose nadir for the stepped clamps was $2.6 \pm 0.3 \mathrm{mmol} / \mathrm{l}$ (range 1.9-3.3), with $2.5 \mathrm{mmol} / \mathrm{l}(22.4 \%)$ or $2.8 \mathrm{mmol} / \mathrm{l}(16.5 \%)$ targeted most often (ESM Fig. 2). Eighty-two per cent of the studies had a glucose nadir $<3.0 \mathrm{mmol} / \mathrm{l}$ (mean $2.5 \pm 0.4 \mathrm{mmol} / \mathrm{l}$, range $1.9-2.9$ ) and $18 \%$ a nadir $\geq 3.0 \mathrm{mmol} / 1$ (mean $3.1 \pm 0.1 \mathrm{mmol} / 1$, range 3.0 3.3).

\section{Discussion}

The main finding of this study is that there is substantial variation in the conduction of hyperinsulinaemic-hypoglycaemic clamps across research groups, particularly in terms of antecedent day preparation, IIRs, number of hypoglycaemic steps, 
hypoglycaemic nadirs and duration of the clamps. The methodology descriptions frequently lacked important information in that less than half of the articles provided all the information needed to evaluate the experiment. Clamps were usually performed in the morning, in fasting condition, with or without some form of standardisation of meals ingested the evening before the clamp. Also, most studies included instructions for people with insulin-treated diabetes to adjust insulin use to avoid (nocturnal) hypoglycaemia prior to clamping. Only one of ten studies imposed other lifestyle restrictions before the clamp, such as refraining from alcohol or caffeine intake, smoking or engaging in strenuous exercise, which can affect glucose homeostasis and responses to hypoglycaemia [9-14], although the duration of these restrictions varied from $12-24 \mathrm{~h}[15,16]$ to $72 \mathrm{~h}[17,18]$. More than half of the experiments were done in participants without diabetes and only around $7 \%$ of participants had type 2 diabetes.

There was an almost 50-fold difference between the highest and lowest IIRs used during the clamps, not including the doubling of the insulin dose that some studies applied to reach the lowest glucose target in stepped clamps. In addition, many studies with participants with type 2 diabetes increased the IIR at the lowest glucose level to ensure it was maintained in the face of insulin resistance and a brisk counterregulatory response. Apart from its effect on glucose requirements, changing the ambient insulin level may affect outcomes, such as the response of counterregulatory hormones. The direction of this change is not known, with some studies observing lower counterregulatory responses of high-dose vs low-dose insulin [19] and others finding the exact opposite, albeit all in healthy men $[20,21]$. Another study, performed in participants with type 1 diabetes, did not find a difference in counterregulatory hormone responses between high- or lowdose IIRs [22]. It should be noted that even the lower insulin doses are often unphysiologically elevated, as this is needed to achieve hypoglycaemia.

Whether the IIRs are calculated on the basis of body weight or BSA does not seem to be relevant. Indeed, the CVs of achieved plasma insulin levels across participants as an estimate of inter-individual insulin variability did not reveal meaningful differences between the two calculation methods. It should be noted, however, that only very few studies included obese individuals, which is relevant because obesity has a much greater effect on the calculated insulin dose when this is based on body weight rather than on BSA. Indeed, for the abovementioned person $\left(75 \mathrm{~kg}\right.$, BSA $\left.1.94 \mathrm{~m}^{2}\right)$, the calculated insulin doses for an IIR of $60 \mathrm{mU} \mathrm{m}^{-2} \mathrm{~min}^{-1}$ or $1.5 \mathrm{mU} \mathrm{kg}^{-1} \mathrm{~min}^{-1}$ are about similar (6.98 vs $\left.6.75 \mathrm{U} / \mathrm{h}\right)$, yet when this person weighs $125 \mathrm{~kg}$ (BSA $2.41 \mathrm{~m}^{2}$ ), these doses equal 8.68 and $11.25 \mathrm{U} / \mathrm{h}$, respectively.

An important indicator of the quality of a glucose clamp is the $\mathrm{CV}$ of achieved plasma glucose levels for each glucose step. The CV reflects the stability of the glucose levels achieved during the clamp; the lower the $\mathrm{CV}$, the more stable the clamp. Although there is no formal consensus on how low the $\mathrm{CV}$ of glucose levels should be during a hypoglycaemic clamp, a CV $<5 \%$ is generally considered desirable [23]. However, this was achieved in only about a third of the articles, and it is plausible that CVs are worse in articles that neither reported nor provided the option to calculate the $\mathrm{CV}$.

Soluble short-acting human insulin was used in the majority of the clamps, although some studies also used porcine insulin [24]. Since rapid-acting insulin analogues and human insulin possess the same pharmacodynamic and pharmacokinetic qualities when administered directly into the bloodstream, the choice of insulin is not considered to affect the outcome of the experiment itself. In the early days of clamp history, a priming insulin dose was often administered to quickly achieve target insulin levels. However, due to the very short $t_{1 / 2}$ of insulin, such a priming dose is probably unnecessary for insulin doses below $\sim 2 \mathrm{mU} \mathrm{kg}^{-1} \mathrm{~min}^{-1}$ $\left(\sim 80 \mathrm{mU} \mathrm{m}^{-2} \mathrm{~min}^{-1}\right)$ [25] and increases the risk that glucose levels fall too quickly. For higher insulin doses, a priming dose has been calculated to shorten the time until reaching steady-state glucose disposal in normoglycaemic glucose clamps [26].

Data on GIRs were not systematically reported. Ideally, they should be reported separately for each glycaemic phase. The GIR during hypoglycaemia is a surrogate marker of the combined counterregulatory hormone response, reflecting the inverse of endogenous glucose appearance resulting from hormonal counterregulation.

Most, but not all, clamps using venous blood sampling applied some form of hand warming to achieve arterialisation of venous blood. Because insulin stimulates glucose uptake in skeletal muscle, peripheral venous samples underestimate, to a variable degree, the glucose concentrations in the blood supplying tissues, most importantly the brain. Proper hand warming opens arteriovenous shunts, resulting in arterialisation of venous blood. Liu et al. found an arteriovenous difference for high and low IIRs of $0.9 \pm 0.1$ and $0.4 \pm 0.1 \mathrm{mmol} / \mathrm{l}$, respectively [27], whereas the arterial-arterialised venous blood difference was about $0.1 \mathrm{mmol} / 1(95 \% \mathrm{CI}-0.2,0.4)$ [28]. The heated hand box method, by which the local temperature is raised in a controllable way to $55-60^{\circ} \mathrm{C}$, is widely used to arterialise venous blood [28]. However, the method by which blood is arterialised is less important, as long as the temperature is sufficiently elevated. Indeed, raising the temperature to $40^{\circ} \mathrm{C}$ with warm blankets was found to be equally effective as the heated hand box [29]. It should be acknowledged that although the arterialisation method is reasonably well validated for glucose, this may not be the case for other compounds (e.g. counterregulatory hormones) [30], indicating that it is not possible to arterialise venous blood completely.

The vast majority of articles reported measurement of glucose levels in plasma, while the remainder of the articles 
reported these to be measured in whole blood. This is important, because, depending on the haematocrit, glucose levels are approximately $11 \%$ lower in whole blood than in plasma [31]. Indeed, most point-of-care glucose meters use standard algorithms to convert glucose measured in whole blood to plasma glucose. Also, the haematocrit may not be stable during clamps, which introduces bias. There is a high risk of misinterpretation when data in studies are compared without considering the source of glucose measurement from either whole blood or plasma. This is particularly relevant for the determination of hypoglycaemic thresholds, e.g. for release of counterregulatory hormones and deterioration of cognitive function, which inform decisions on the cut-offs used in the current classification for hypoglycaemia [8].

In 2017, the IHSG proposed glucose levels $<3.0 \mathrm{mmol} / 1$ $(<54 \mathrm{mg} / \mathrm{dl})$, coined as clinically important hypoglycaemia, to be reported in clinical studies, so as to enable comparing of the effectiveness of interventions with hypoglycaemia as an endpoint [8]. The majority of the clamp studies that we investigated included a glucose level around this value, but about one of every four single-step clamps used a glucose nadir that was substantially higher (up to $4.3 \mathrm{mmol} / \mathrm{l}$ ). The $3.0 \mathrm{mmol} / \mathrm{l}$ threshold level is the result of consensus and analyses are currently being conducted to refine and solidify the level [32]. For comparability reasons, it could be argued to always include such a refined threshold value in future hypoglycaemic glucose clamps, whether involving one or multiple steps.

There was also substantial variability with respect to the duration of the hypoglycaemic steps used in both the singlestep and the stepped clamps. Whereas a duration of hypoglycaemia as short as $5 \mathrm{~min}$ (at $2.9 \mathrm{mmol} / \mathrm{l}$ ) has been reported to initiate the process of habituation [33], a common protocol in clamp studies is to take approximately $20 \mathrm{~min}$ to reach that level and another $20 \mathrm{~min}$ to revert back from hypoglycaemia. The CGM definition of hypoglycaemia requires such an event to last for a minimum of $15 \mathrm{~min}$, with prolonged hypoglycaemia defined as an episode of at least $120 \mathrm{~min}$ [34]. On the other hand, long duration of hypoglycaemia can be seen as highly unphysiological, affecting both the counterregulatory response [35] and potentially other outcomes. It seems plausible that the longer the duration of the hypoglycaemic phase, the more discomfort this may cause, so that a maximum duration of $30-60 \mathrm{~min}$ seems reasonable.

A total of 11 studies in this systematic review were performed in children (age range, 6.4-18.0 years), ten of which included children with type 1 diabetes. The methodology of the study protocols in the paediatric population was very similar to those of adult populations with respect to IIRs, glucose targets and overall duration. However, since the number of studies is small, extrapolating our findings in the adult population to children should be done with caution, particularly since the younger age group $(<12$ years $)$ is underrepresented.

This review has limitations. Due to the large number of articles, some of which dated back $>40$ years, we only extracted information from the article itself and chose not to contact the authors. Also, we focused on type 1 and type 2 diabetes. Studies involving people with insulinomas [36], pancreatic transplantation [37], gastric bypass [38] or other conditions unrelated to diabetes were therefore excluded to minimise potential further methodological variability. Information about the use of albumin or the participants' blood to prevent insulin from sticking to the infusion sets was very sparse. Similarly, very few studies provided information about the addition of potassium to the glucose/insulin infusion to avoid hypokalaemia and the potential arrhythmia-provoking consequences [39]. However, the lack of such information may suggest these adverse events to be extremely uncommon. More than $60 \%$ of the articles lacked other important information, which may reduce the validity for assessing data and comparing studies.

In conclusion, there is substantial variation in how hyperinsulinaemic-hypoglycaemic clamps have been conducted and reported in the past $>40$ years. This variation may potentially impact or raise questions about the validity of outcomes, and certainly makes it difficult, if not impossible, to compare results across studies. International consensus to standardise the design of both single-step and stepped clamps is therefore urgently needed.

Supplementary Information The online version contains peer-reviewed but unedited supplementary material available at https://doi.org/10.1007/ s00125-020-05361-8.

Acknowledgements The authors would like to acknowledge the support of J. Meelby, Information Specialist, Library and Information Services at Nordsjællands Hospital, Denmark, for her assistance with the systematic search strategy. Some of the data were presented as an abstract at the Annual Dutch Diabetes Research Meeting in 2019 and as a presentation at the EASD Annual Meeting 2020.

Data availability All data generated or analysed during this study are included in this published article (and its supplementary information files) (ESM Methods, ESM Table 1).

Funding This review has received funding from the Innovative Medicines Initiative 2 Joint Undertaking (JU) under grant agreement No. 777460. The JU receives support from the European Union's Horizon 2020 research and innovation programme and the EFPIA, the T1D Exchange, JDRF, the International Diabetes Federation (IDF), and the Leona M. and Harry B. Helmsley Charitable Trust.

Authors' relationships and activities TWF: None. CEMV: None. PLK has received lecture fees from AstraZeneca. RJM has served on advisory boards for Novo Nordisk and Sanofi, and has received lecture fees from Novo Nordisk and Sanofi. MLE has served on advisory boards and/or received speaker/travel support from Novo Nordisk, Medtronic, Abbott Diabetes Care, Roche, Pila Pharma, Dexcom, Eli Lilly, Astra Zeneca and Zucara. SH has served on advisory boards for Sanofi-Aventis, Eli Lilly, 
Novo Nordisk and Zealand Pharma, and received lecture fees from Novo Nordisk and AstraZeneca. TRP has received research support from AstraZeneca and Novo Nordisk (paid directly to the university); has served on advisory boards for Adocia, Arecor, AstraZeneca, Eli Lilly, Novo Nordisk and Sanofi; and has received lecture fees from Novo Nordisk. BEDG has received research support from Novo Nordisk. UPB has served on advisory boards for AstraZeneca, Bristol-Myers Squibb, Sanofi-Aventis, Novo Nordisk and Zealand Pharma, and has received lecture fees from AstraZeneca, Bristol-Myers Squibb, Sanofi-Aventis and Novo Nordisk. The authors declare that there are no relationships or activities that might bias, or be perceived to bias, their work.

Contribution statement TWF, CEMV, UP-B and BEDG designed the study. TWF and CEMV selected the articles, appraised the articles and extracted data for the review. CEMV analysed the data. TWF and CEMV wrote the first version of the manuscript with input from UP-B and BEDG. All other authors contributed to interpretation of the data, critical reading, and providing comments and edits to the manuscript for important intellectual content. TWF and CEMV are guarantors of the work. All authors gave final approval of the version to be published.

Open Access This article is licensed under a Creative Commons Attribution 4.0 International License, which permits use, sharing, adaptation, distribution and reproduction in any medium or format, as long as you give appropriate credit to the original author(s) and the source, provide a link to the Creative Commons licence, and indicate if changes were made. The images or other third party material in this article are included in the article's Creative Commons licence, unless indicated otherwise in a credit line to the material. If material is not included in the article's Creative Commons licence and your intended use is not permitted by statutory regulation or exceeds the permitted use, you will need to obtain permission directly from the copyright holder. To view a copy of this licence, visit http://creativecommons.org/licenses/by/4.0/.

\section{References}

1. Cryer PE, Davis SN, Shamoon H (2003) Hypoglycemia in diabetes. Diabetes Care 26(6):1902-1912. https://doi.org/10.2337/diacare. 26.6.1902

2. Sherwin RS, Kramer KJ, Tobin JD et al (1974) A model of the kinetics of insulin in man. J Clin Invest 53(5):1481-1492. https:// doi.org/10.1172/JCI107697

3. DeFronzo RA, Tobin JD, Andres R (1979) Glucose clamp technique: a method for quantifying insulin secretion and resistance. Am J Physiol Metab 237(3):E214

4. Verdonk CA, Rizza RA, Nelson RL, Go VL, Gerich JE, F. J. Service (1980) Interaction of fat-stimulated gastric inhibitory polypeptide on pancreatic alpha and beta cell function. J Clin Invest 65(5):1119-1125. https://doi.org/10.1172/JCI109765

5. Verdonk CA, Rizza RA, Westland RE, Nelson RL, Gerich JE, F. J. Service (1980) Glucose clamping using the biostator GCIIS. Horm Metab Res 12(4):133-135

6. Liberati A, Altman DG, Tetzlaff J et al (2009) The PRISMA statement for reporting systematic reviews and meta-analyses of studies that evaluate health care interventions: Explanation and elaboration. J Clin Epidemiol 62(10):e1-e34. https://doi.org/10.1016/j.jclinepi. 2009.06.006

7. Kim HS (2016) Blood glucose measurement: Is serum equal to plasma? Diabetes Metab J 40(5)365-366. https://doi.org/10.4093/ dmj.2016.40.5.365
8. IHSG (2017) Glucose concentrations of less than $3.0 \mathrm{mmol} / \mathrm{L}$ (54 $\mathrm{mg} / \mathrm{dL}$ ) should be reported in clinical trials: a joint position statement of the American diabetes association and the European association for the study of diabetes. Diabetes Care 40(1):155-157

9. van de Wiel A (2004) Diabetes mellitus ad alchohol. Diabetes Metab Res Rev 20(4):263-267. https://doi.org/10.1002/dmrr.492

10. Benowitz NL, Burbank AD (2016) Cardiovascular toxicity of nicotine: implications for electronic cigarette use. Trends Cardiovasc Med 26(6):515-523. https://doi.org/10.1016/j.tcm.2016.03.001

11. Bird SR, Hawley JA (2017) Update on the effects of physical activity on insulin sensitivity in humans. BMJ Open Sport Exerc Med 2(1). https://doi.org/10.1136/bmjsem-2016-000143

12. Keijzers GB, De Galan BE, Tack CJ, Smits P (2002) Caffeine can decrease insulin sensitivity in humans. Diabetes Care 25(2):364369. https://doi.org/10.2337/diacare.25.2.364

13. Watson JM, Jenkins EJE, Hamilton P, Lunt MJ, Kerr D (2000) Influence of caffeine on the frequency and perception of hypoglycemia in free-living patients with type 1 diabetes. Diabetes Care 23(4):455-459. https://doi.org/10.2337/diacare.23.4.455

14. Eliasson B (2003) Cigarette smoking and diabetes. Prog Cardiovasc Dis 45(5):405-413. https://doi.org/10.1016/S0033-0620(03) 80004-X

15. Peacey SR, George E, Rostami-Hodjegan A et al (1996) Similar physiological and symptomatic responses to sulphonylurea and insulin induced hypoglycaemia in normal subjects. Diabet Med 13(7):634-641. https://doi.org/10.1002/(SICI)1096-9136(199607) 13:7<634::AID-DIA136>3.0.CO;2-Z

16. Ang M, Meyer C, Brendel MD, Bretzel RG, Linn T (2014) Magnitude and mechanisms of glucose counterregulation following islet transplantation in patients with type 1 diabetes suffering from severe hypoglycaemic episodes. Diabetologia 57(3):623-632. https://doi.org/10.1007/s00125-013-3120-9

17. Rooijackers HM, Wiegers EC, van der Graaf M et al (2017) A single bout of high-intensity interval training reduces awareness of subsequent hypoglycemia in patients with type 1 diabetes. Diabetes 66(7):1990-1998. https://doi.org/10.2337/db16-1535

18. De Galan BE, Tack CJ, Lenders JW, Lutterman JA, Smits P (2003) Effect of 2 weeks of theophylline on glucose counterregulation in patients with type 1 diabetes and unawareness of hypoglycemia. Clin Pharmacol Ther 74(1):77-84. https://doi.org/10.1016/S00099236(03)00093-6

19. Diamond MP, Hallarman L, Starick-Zych K et al (1991) Suppression of counterregulatory hormone response to hypoglycemia by insulin per se. J Clin Endocrinol Metab 72(6):1388-1390. https://doi.org/10.1210/jcem-72-6-1388

20. Davis SN, Goldstein RE, Jacobs J, Price L, Wolfe R, Cherrington AD (1993) The effects of differing insulin levels on the hormonal and metabolic response to equivalent hypoglycemia in normal humans. Diabetes 42(2):263-272. https://doi.org/10.2337/diab.42. 2.263

21. Mellman MJ, Davis MR, Shamoon H (1992) Effect of physiological hyperinsulinemia on counterregulatory hormone responses during hypoglycemia in humans. J Clin Endocrinol Metab 75(5): 1293-1297. https://doi.org/10.1210/jcem.75.5.1430091

22. Davis SN, Goldstein RE, Price L, Jacobs J, Cherrington AD (1993) The effects of insulin on the counterregulatory response to equivalent hypoglycemia in patients with insulin-dependent diabetes mellitus. J Clin Endocrinol Metab 77(5):1300-1307. https://doi. org/10.1210/jcem.77.5.8077324

23. Benesch C, Heise T, Klein O, Heinemann L, Arnolds S (2015) How to assess the quality of glucose clamps? Evaluation of clamps performed with ClampArt, a novel automated clamp device. J Diabetes Sci Technol 9(4):792-800. https://doi.org/10.1177/ 1932296815576957

24. Ryan CM, Dulay D, Suprasongsin C, Becker DJ (2002) Detection of symptoms by adolescents and young adults with type 1 diabetes 
during experimental induction of mild hypoglycemia: Role of hormonal and psychological variables. Diabetes Care 25(5):852858. https://doi.org/10.2337/diacare.25.5.852

25. Kitabchi AE, Murphy MB, Spencer J, Matteri R, Karas J (2008) Is a priming dose of insulin necessary in a low-dose insulin protocol for the treatment of diabetic ketoacidosis? Diabetes Care 31(11):20812085. https://doi.org/10.2337/dc08-0509

26. Hovorka R, Powrie JK, Jones RH (1994) A simulation study to determine optimal insulin priming during glucose clamp studies. Comput Methods Prog Biomed 41(3-4):231-241

27. Liu D, Moberg E, Kollind M, Lins PE, Adamson U (1991) A high concentration of circulating insulin suppresses the glucagon response to hypoglycemia in normal man. J Clin Endocrinol Metab 73(5):1123-1128. https://doi.org/10.1210/jcem-73-5-1123

28. Liu D, Moberg E, Kollind M, Lins PE, Adamson U, Macdonald IA (1992) Arterial, arterialized venous, venous and capillary blood glucose measurements in normal man during hyperinsulinaemic euglycaemia and hypoglycaemia. Diabetologia 35(3):287-290. https://doi.org/10.1007/BF00400932

29. Gallen IW, Macdonald IA (1990) Effect of two methods of hand heating on body temperature, forearm blood flow, and deep venous oxygen saturation. Am J Physiol Endocrinol Metab 259(5):22-25

30. Nauck MA, Ließ H, Siegel EG, Niedmann PD, Creutzfeldt W (1992) Critical evaluation of the 'heated-hand-technique' for obtaining 'arterialized' venous blood: incomplete arterialization and alterations in glucagon responses. Clin Physiol 12(5):537552. https://doi.org/10.1111/j.1475-097X.1992.tb00357.x

31. D'orazio P, Burnett RW, Fogh-Andersen N et al (2006) Approved IFCC recommendation on reporting results for blood glucose: International Federation of Clinical Chemistry and Laboratory Medicine Scientific Division, Working group on selective electrodes and point-of-care testing (IFCC-SD-WG-SEPOCT). Clin Chem Lab Med 44(12):1486-1490. https://doi.org/10.1515/ CCLM.2006.275
32. de Galan BE, McCrimmon RJ, Ibberson M et al (2020) Reducing the burden of hypoglycaemia in people with diabetes through increased understanding: design of the Hypoglycaemia REdefining SOLutions for better liVEs (Hypo-RESOLVE) project. Diabet Med 37(6):1066-1073. https://doi.org/10.1111/dme.14240

33. Davis SN, Mann S, Galassetti P et al (2000) Effects of differing durations of antecedent hypoglycemia on counterregulatory responses to subsequent hypoglycemia in normal humans. Diabetes 49(11):1897-1903. https://doi.org/10.2337/diabetes.49. 11.1897

34. Danne T, Nimri R, Battelino T, et al (2017) International consensus on use of continuous glucose monitoring. Diabetes Care 40(12): 1631-1640. https://doi.org/10.2337/dc17-1600

35. Kerr D, Macdonald IA, Tattersali RB (1989) Influence of duration of hypoglycemia on the hormonal counterregulatory response in normal subjects. J Clin Endocrinol Metab 68(6):1118-1122. https://doi.org/10.1210/jcem-68-6-1118

36. Mitrakou A, Fanelli C, Veneman T et al (1993) Reversibility of unawareness of hypoglycemia in patients with Insulinomas. N Eng1 J Med 329(12):834-839. https://doi.org/10.1056/ NEJM199309163291203

37. Robertson RP, Sutherland DER, Seaquist ER, Lanz KJ (2003) Glucagon, catecholamine, and symptom responses to hypoglycemia in living donors of pancreas segments. Diabetes 52(7):1689 1694. https://doi.org/10.2337/diabetes.52.7.1689

38. Abrahamsson N, Börjesson JL, Sundbom M, Wiklund U, Karlsson FA, Eriksson JW (2016) Gastric bypass reduces symptoms and hormonal responses in hypoglycemia. Diabetes 65(9):2667-2675. https://doi.org/10.2337/db16-0341

39. Viera AJ, Wouk N (2015) Potassium disorders: hypokalemia and hyperkalemia. Am Fam Physician 92(6):487-495

Publisher's note Springer Nature remains neutral with regard to jurisdictional claims in published maps and institutional affiliations. 